\title{
MAGNESIUM SULPHATE INFUSION PREVENTS SHIVERING DURING SPINAL ANAESTHESIA: A RANDOMISED DOUBLE BLINDED CONTROLLED STUDY
}

\author{
Mariappan Gomathi', Raju Sudhakar ${ }^{2}$
}

${ }_{1}^{1}$ Associate Professor, Department of Anaesthesiology, Govt. Vellore Medical College Hospital, Adukkamparai, Vellore. ${ }^{2}$ Associate Professor, Department of Anaesthesiology, Govt. Vellore Medical College Hospital, Adukkamparai, Vellore.

\begin{abstract}
Spinal anaesthesia is the most common form of anaesthesia in our hospital. Shivering is a very common complication in patients undergoing surgery under spinal anaesthesia. Shivering increases expenditure of cardiac and systemic energy resulting in increased oxygen consumption and carbon dioxide production, lactic acidosis and raises intraocular and intracranial pressure. It also interferes with haemodynamic monitoring intraoperatively. Regional anaesthesia produces vasodilatation, which facilitates core to peripheral distribution of heat. It also increases sweating threshold and decreases vasoconstriction and shivering threshold. Intra- and postoperative management of shivering is usually done by external heating (Forced air warming, warming blankets), warmed fluids or pharmacological intervention. Prevention and treatment of established shivering should be regarded as clinically relevant intervention in the perioperative period. Therefore, a randomized double-blind control study was done using magnesium sulphate infusion in the prevention of shivering in our hospital. The aim of our study is to assess the efficacy of magnesium sulphate when used for prevention of shivering following spinal anaesthesia.
\end{abstract}

METHODS

Institutional Ethical Committee approval and informed consent were obtained from all patients.

\section{INCLUSION CRITERIA}

80 patients of ASA 1 and 2 belonging to either sex, aged between 18-65 years undergoing lower abdominal and lower limb surgeries were included in the study.

\section{EXCLUSION CRITERIA}

Patients suffering from neuromuscular disease, hyperthyroidism, cardiopulmonary disease, psychological disease, refusal to participate or temperature more than $38^{*} \mathrm{C}$ or less than $36.5^{*} \mathrm{C}$. The patients were randomized into 2 groups namely Group M and Group C. Group M - Each of Group $\mathrm{M}$ patients were designated to receive $2 \mathrm{gms}(4 \mathrm{~mL})$ of magnesium sulphate in the preloading fluid over a period of 20-30 minutes. Group C - Each of Group $\mathrm{C}$ patients were designated to receive $4 \mathrm{~mL}$ of normal saline as control in the preloading fluid over a period of 20 - 30 minutes. Following a detailed pre-anaesthetic checkup along with relevant investigations, patients were brought to the operation theatre and connected to monitors. Then the vital signs of the patients including heart rate, temperature, non-invasive blood pressure, respiratory rate and Sp02 were continuously monitored and recorded. Both group of patients were pre-loaded with $15 \mathrm{~mL} / \mathrm{kg}$ of Ringer lactate before giving spinal anaesthesia.

\section{GROUP M}

The study drug of $4 \mathrm{~mL}$ of Inj. Magnesium Sulphate was coded and presented to the anaesthetist not involved in the management of the patient and administered by intravenous infusion by adding it in the preloading fluid before spinal anaesthesia over a period of 20-30 minutes.

\section{GROUP C}

The control drug of $4 \mathrm{~mL}$ of normal saline was coded and presented to the anaesthetist not involved in the management of the patient and administered by intravenous infusion by adding it in the preloading fluid before spinal anaesthesia over a period of $20-30$ minutes. The temperature of the operation theatre was maintained at $22-24^{*} \mathrm{C}$. After preloading, all patients were administered intrathecal injection of $12.5 \mathrm{mg}$ of $0.5 \%$ preservative free heavy Bupivacaine. Intraoperative patients were monitored for shivering along with other vital parameters. Adequacy of subarachnoid block was ensured. Core and skin temperatures were also recorded.

\section{MAIN RESULTS}

Total incidence of shivering grade $3 / 4$ was $5 \%$ in Group M and 30\% in Group C $(\mathrm{p}<0.01)$. Magnesium sulphate significantly reduced the incidence and intensity of shivering. The use of rescue drug Inj. Pethidine was more in Group C (30\%) compared to 5\% in Group C ( $p<0.01)$.

\section{CONCLUSION}

For patients undergoing spinal anaesthesia, prophylactic Inj. Magnesium Sulphate infusion lowered incidence of shivering. When shivering did occur, rescue drug Inj. Pethidine proved to be an effective treatment with minimal side effects.

\section{KEYWORDS}

Prophylactic; Magnesium Sulphate; Shivering; Spinal Anaesthesia.

HOW TO CITE THIS ARTICLE: Gomathi M, Sudhakar R. Magnesium sulphate infusion prevents shivering during spinal anaesthesia: a randomised double blinded controlled study. J. Evolution Med. Dent. Sci. 2016;5(65):4614-4618, DOI: 10.14260/jemds/2016/1052

Financial or Other, Competing Interest: None.

Submission 19-07-2016, Peer Review 01-08-2016,

Acceptance 04-08-2016, Published 12-08-2016.

Corresponding Author:

Dr. Mariappan Gomathi,

Associate Professor,

Department of Anaesthesiology,

Government Vellore Medical College Hospital,

Adukkamparai,

Vellore-632011.

E-mail: suresh_goms@yahoo.com

DOI: $10.14260 /$ jemds $/ 2016 / 1052$

\section{INTRODUCTION}

Shivering is a frequent complication following neuraxial anaesthesia. It is an involuntary, oscillatory muscular activity that augments metabolic heat production. Shivering may occur as a response to hypothermia. However, it may also occur in normothermic patients. ${ }^{[1]}$ Regional anaesthesia impairs both central and peripheral thermoregulatory control. In patients becoming sufficiently hypothermic, shivering may appear and is often disturbing to both patients and medical staff.[2] Shivering may interfere with monitoring of heart rate, blood pressure and oxygen saturation. 
It is associated with substantial adrenergic activation. ${ }^{[3]}$ It increases oxygen consumption, lactic acidosis, carbon dioxide production and metabolic rate by up to $400 \%$; thus, it may cause problems in patients with low cardiac and pulmonary reserves.[1] Numerous studies have tested the efficacy of a large variety of interventions to prevent shivering in normothermic or hypothermic surgical patients, but the relative efficacy of these interventions, however, remains unclear. ${ }^{[4]}$ As the incidence of hypotension is high during regional anaesthesia, hypotensive agents including clonidine and urapidil may not be appropriate in preventing shivering. In addition, Pethidine (the most widely used agent) and tramadol may cause nausea and vomiting and respiratory depression during and after regional anaesthesia. The hypertensive and tachycardiac effects of ketamine limits its use.[5] The search continues for drugs that sufficiently improve thermoregulatory tolerance without simultaneously producing excessive sedation or respiratory depression. Intravenous magnesium has been shown to suppress postoperative shivering suggesting that the agent reduces the shivering threshold.[6] Recently, the addition of intravenous magnesium sulphate to a pharmacological antishivering regimen increased the cooling rate in unanaesthetised volunteers. ${ }^{[7]}$ The drug not only exerts a central effect, ${ }^{[8]}$ but is also a mild muscle relaxant ${ }^{[9]}$ and may thus simultaneously reduce the gain of shivering (Incremental shivering intensity with progressing hypothermia).[10]

This study was designed to assess the effectiveness of magnesium sulphate when given prophylactically in the control of shivering.

\section{MATERIALS AND METHODS}

Institutional Ethical Committee approval and informed consent were obtained from all patients.

\section{Inclusion Criteria}

80 patients of ASA 1 and 2 belonging to either sex, aged between 18-65 years undergoing lower abdominal and lower limb surgeries were included in the study.

\section{Exclusion Criteria}

Patients suffering from neuromuscular disease, hyperthyroidism, cardiopulmonary disease, psychological disease, refusal to participate or temperature more than $38^{*} \mathrm{C}$ or less than $36.5^{*} \mathrm{C}$.

The patients were randomized into 2 groups namely Group $\mathrm{M}$ and Group C.

\section{Group M}

Each of Group M patients were designated to receive 2 grams ( $4 \mathrm{~mL}$ ) of magnesium sulphate in the preloading fluid over a period of 20-30 minutes.

\section{Group C}

Each of Group C patients were designated to receive $4 \mathrm{~mL}$ of normal saline as control in the preloading fluid over a period of 20-30 minutes.

Following a detailed pre-anaesthetic checkup along with relevant investigations, patients were brought to the operation theatre and connected to monitors. Tympanic (core) temperature was measured by an ear thermometer. The aural probe was inserted until the patient felt it touching the tympanic membrane, the probe was then securely taped in place and the aural canal was occluded with cotton and a gauze bandage was positioned over the external ear. Axillary (Skin) temperature was measured by an axillary thermometer. Temperature difference was measured (DT=core temperature minus skin temperature). Core temperature less than $36 \mathrm{C}$ was considered hypothermia. The vital signs of the patients including heart rate, temperature, non-invasive blood pressure, respiratory rate and $\mathrm{SpO} 2$ were continuously monitored and recorded.

Both Groups (Group M and Group C) of patients were preloaded with $15 \mathrm{~mL} / \mathrm{kg}$ of Ringer lactate before spinal anaesthesia with the inclusion of study drugs in the preloading fluid.

\section{Group M}

The study drug of $4 \mathrm{~mL}$ of Inj. Magnesium Sulphate was coded and presented to the anaesthetist not involved in the management of the patient and administered by intravenous infusion by adding it in the preloading fluid before the spinal anaesthesia over a period of 20-30 minutes. During infusion of Inj. Magnesium sulphate, the vital signs of the patients including heart rate, ECG, temperature, non-invasive blood pressure, respiratory rate and $\mathrm{SpO} 2$ were continuously monitored and recorded to pick up early the side effects of magnesium sulphate injection like heart rhythm disturbances, breathing difficulties, poor reflexes confusion, weakness, flushing, sweating, lowered blood pressure or headache.

The infusion was stopped if any adverse effect was observed in the patient, patient treated accordingly and patient excluded from study.

\section{Group C}

The control drug of $4 \mathrm{~mL}$ of normal saline was coded and presented to the anaesthetist not involved in the management of the patient and administered by intravenous infusion by adding it in the preloading fluid before the spinal anaesthesia over a period of 20-30 minutes.

The ambient temperature was maintained at 22-24 C. Spinal anaesthesia was performed at either L3/4 or L4/5 interspaces. Hyperbaric bupivacaine, $12.5 \mathrm{mg}$ was injected using a 25-gauge spinal needle with the patients in the lateral decubitus position. Adequacy of spinal anaesthesia was ensured. Level of sensory blockade was assessed by pinprick and motor blockade by Bromage scale.[11]

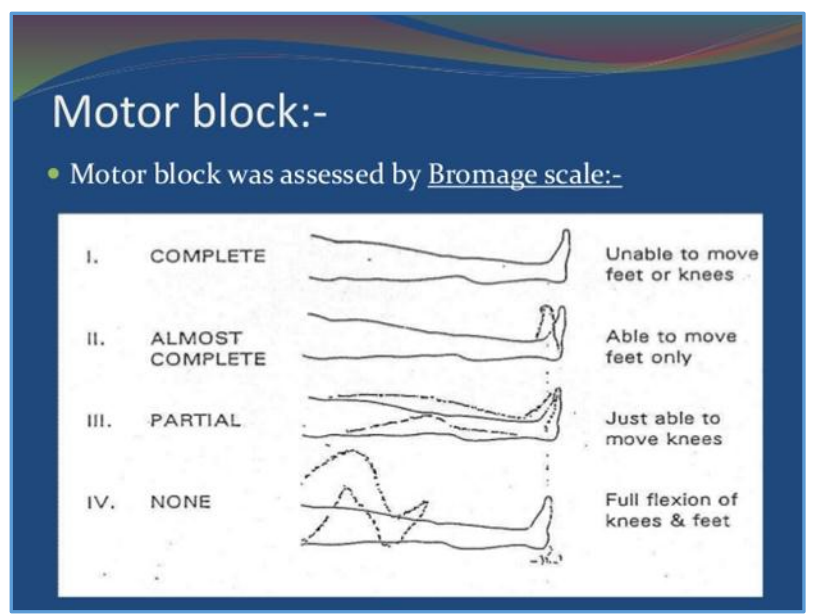


Intraoperatively, patients were monitored for shivering along with other vital parameters. Core and skin temperatures were also recorded.

Intensity of Shivering was graded as per Crossley and Mahajan Scale

\begin{tabular}{|c|c|}
\hline Scale & Description \\
\hline 0 & No Shivering \\
\hline 1 & $\begin{array}{c}\text { No visible muscle activity but piloerection, } \\
\text { peripheral vasoconstriction or both are present } \\
\text { (other causes excluded) }\end{array}$ \\
\hline 2 & Muscular activity in only one muscle group \\
\hline 3 & $\begin{array}{c}\text { Moderate muscular activity in more than one } \\
\text { muscle group, but no generalized shaking }\end{array}$ \\
\hline 4 & $\begin{array}{c}\text { Violent muscular activity that involves the whole } \\
\text { body. }\end{array}$ \\
\hline
\end{tabular}

Shivering grade 3/4 was regarded as significant.

Patients were given Inj. Pethidine $25 \mathrm{mg}$ IV when shivering was significant as a rescue drug. At the end of the surgical procedure, the patients were shifted to Post Anaesthesia Care Unit for monitoring purpose.

\section{Rescue Drug}

Patients were given Inj. Pethidine Hydrochloride 25 mg IV when shivering was significant as a rescue drug.

Supplemental oxygen was delivered via a nasal cannula ( 4 $\mathrm{L} / \mathrm{min}$ ) if arterial blood saturation fell below 90\%. These parameters were recorded preoperative after induction of anaesthesia, every 10 mins. till the end of surgery, then every 10 mins. Postoperative until 2 segments regression of the sensory blockade. Shivering was assessed after completion of subarachnoid injection until the patient was discharged after 2 segments regression of sensory blockade. Postoperatively, all patients were transferred to postoperative care unit (PACU) and monitored every 10 mins. until discharge.

Statistical analysis Data were analysed by using SPSS. (The Statistical Package for Social Sciences) version 17.0 software. Categorical data including total incidence of shivering and side effects were analysed using chi square. Independent t-test was used for quantitative data for comparison between two groups; paired t-test for quantitative data within each group; one-way ANOVA for quantitative data comparison between the 2 groups; Fisher's exact test for categorical data between the study groups; Mann-Whitney test for quantitative nonparametric data between two groups; Kruskal-Wallis Htest for quantitative nonparametric data between three groups; and Spearman correlation for correlation testing. Pvalue $<0.05$ was considered significant.

\section{RESULTS}

A total of 80 patients completed this study, 40 in each group. The two groups were similar as regards age, weight, height and ASA physical status (Table 1). They were also comparable in duration of anaesthesia, surgery and amount of crystalloid administered. There was insignificant change as regards to mean heart rate, mean arterial blood pressure, oxygen saturation, and mean respiratory rate in the two groups throughout the study period. There was no correlation between patients who shivered and core temperature. Total incidence of shivering grade $3 / 4$ was $5 \%$ in Group $\mathrm{M}$ and 30\% in Group C (Table 2). Shivering was considered significant when the patient shivered at least to Grade 3.[12] Use of rescue Inj. Pethidine was more in Group C (30\%) compared to 5\% in Group M ( $\mathrm{p}<0.05)$.

\begin{tabular}{|c|c|c|c|}
\hline & & Group M & Group C \\
\hline $\begin{array}{l}\text { Sample size } \\
\mathrm{n}\end{array}$ & & $n=40$ & $n=40$ \\
\hline Age in years & & $40.9+21$ & $41.6+21.4$ \\
\hline Weight (kg) & & $53+20.1$ & $53+19.2$ \\
\hline \multirow{2}{*}{ Sex n (\%) } & & $\begin{array}{c}\text { Males } 18 \\
(45 \%)\end{array}$ & $\begin{array}{l}\text { Males } 20 \\
(50 \%)\end{array}$ \\
\hline & & $\begin{array}{c}\text { Females } 22 \\
(55 \%)\end{array}$ & $\begin{array}{c}\text { Females } 20 \\
(50 \%)\end{array}$ \\
\hline \multirow{3}{*}{$\begin{array}{c}\text { Type of } \\
\text { operation } \\
\text { n (\%) }\end{array}$} & $\begin{array}{l}\text { General } \\
\text { surgery }\end{array}$ & $16(40 \%)$ & $12(30 \%)$ \\
\hline & Orthopaedic & $18(45 \%)$ & $20(50 \%)$ \\
\hline & Urologic & $6(15 \%)$ & $8(20 \%)$ \\
\hline \multicolumn{4}{|c|}{$\begin{array}{c}\text { Table 1: Demographic Data and Type of Operation } \\
\text { in the Study Groups }\end{array}$} \\
\hline
\end{tabular}

Data are presented as Mean \pm SD. $n=$ number.

\begin{tabular}{|l|c|c|}
\hline & Group M & Group C \\
\hline Total Number of patients & $\mathrm{n}=40$ & $\mathrm{n}=40$ \\
\hline Incidence of shivering $\%$ & $5 \%(\mathrm{n}=2)$ & $30 \%(\mathrm{n}=12)$ \\
\hline \multicolumn{3}{|c|}{ Table 2 } \\
\hline
\end{tabular}

\begin{tabular}{|c|c|c|c|}
\hline & \multicolumn{2}{|c|}{$\begin{array}{c}\text { Group M } \\
(n=40)\end{array}$} & $\begin{array}{c}\text { Group C } \\
(n=40)\end{array}$ \\
\hline $\begin{array}{l}\text { Anaesthesia } \\
\text { Duration } \\
\text { (min.) }\end{array}$ & \multicolumn{2}{|c|}{$75.5 \pm 17$} & $71.5 \pm 14.6$ \\
\hline $\begin{array}{l}\text { Surgery } \\
\text { Duration } \\
\text { (min.) }\end{array}$ & \multicolumn{2}{|c|}{$71 \pm 16$} & $69.3 \pm 13.9$ \\
\hline $\begin{array}{l}\text { Crystalloids } \\
\text { (cc) (Intra- } \\
\text { operative) }\end{array}$ & \multicolumn{2}{|c|}{$1050 \pm 426.1$} & $1025 \pm 372.6$ \\
\hline \multirow{4}{*}{$\begin{array}{c}\text { Drug } \\
\text { Administration }\end{array}$} & None & $\begin{array}{c}n=33 \\
(82.5 \%)\end{array}$ & $\mathrm{n}=23(57.5 \%)$ \\
\hline & Ephedrine & $\begin{array}{c}n=5 \\
(12.5 \%)\end{array}$ & $n=5(12.5 \%)$ \\
\hline & Atropine & $\begin{array}{c}\mathrm{n}=0 \\
(0 \%)\end{array}$ & $\mathrm{n}=0(0 \%)$ \\
\hline & Pethidine & $n=2(5 \%)$ & $\mathrm{n}=12(30 \%)$ \\
\hline Shivering 3/4 & \multicolumn{2}{|c|}{$\mathrm{n}=2(5 \%)$} & $\mathrm{n}=12(30 \%)$ \\
\hline
\end{tabular}

Data are presented as Mean $\pm S D, n=$ number.

${ }^{*} \mathrm{p}<0.001$ Group M vs. Group C.

\section{DISCUSSION}

Post-anaesthesia shivering is very common following neuraxial anaesthesia. In our study, shivering was reported in $30 \%$ of patients in the control group $\mathrm{C}$ and $5 \%$ in the prophylactic groups similar to incidence reported on earlier studies.[13] The exact mechanism of shivering during regional anaesthesia has not been fully established. Post-spinal shivering is probably a combination of both thermoregulatory and non-thermoregulatory shivering.[1] Thermoregulatory 
shivering is a response to hypothermia due to redistribution of body heat from the core to the periphery. ${ }^{[14]}$ The resultant vasoconstriction and shivering are restricted to the upper body due to the sympathetic and somatic neural blockade below the level of spinal blockade.[15]

In our study, we found that post-spinal shivering may appear within minutes after injection of local anaesthetic and long before sufficient time has elapsed for significant heat loss to have occurred; therefore, other mechanisms of shivering exist. The same finding led Bromage.[11] to postulate that spinal cord response is secondary to misinterpretation of afferent thermal clues due to differential blockade of warm and cold sensation, which is also supported by Kaoy et al.[16]

Also, shivering has been reported in normothermic patients suggesting that inhibited spinal reflexes, apprehension, decreased sympathetic activity, pyrogen release, adrenal gland suppression and respiratory alkalosis are also involved.[17]

A wide variety of agents with different mechanisms of action including opioids, non-opioid analgesics, 5-HT3 antagonists, a2 adrenoceptor agonists and cholinomimetic agents have been studied in an attempt to prevent or treat shivering, but unfortunately there is no "gold-standard" drug for the prevention of shivering.

The search continues for drugs that sufficiently reduce the shivering threshold and improve thermoregulatory tolerance without simultaneously producing excessive sedation or respiratory depression. ${ }^{[4]}$ Magnesium is a naturally occurring calcium competitor and a noncompetitive antagonist of $\mathrm{N}$ methyl-D-aspartate (NMDA) receptors.[18] The exact protective mechanism of $\mathrm{MgSO} 4$ remains uncertain; magnesium prevents or controls convulsions by blocking neuromuscular transmission and decreasing the release of acetylcholine at the motor nerve terminals.[19] Parenteral magnesium sulphate is the drug of choice for the prevention and treatment of eclamptic convulsions. ${ }^{[20]}$ It is an effective treatment for postoperative shivering following general anaesthesia.[6] Magnesium has been reported to reduce shivering threshold in healthy volunteers,[21] as treatments that reduce the shivering threshold by a few tenths of a degree Celsius may be sufficient to attenuate postoperative shivering.[22]

In our study, core hypothermia occurred in both groups. It is likely that larger doses of MgSO4 would produce greater thermoregulatory effects, but carries a greater risk of complications as the thermoregulatory response to most IV drugs is linear with plasma concentration. ${ }^{[23]}$

Patients receiving prophylactic magnesium in our study had a lower incidence of shivering than the control group. This is due to its mild muscle relaxant effect, thereby reducing the gain of shivering (Incremental shivering intensity with progressing hypothermia). Magnesium has been suggested as a possible means of resolving muscle rigidity and spasm in tetanus.[24]

An earlier study by Gozedemir et al achieved an incidence of shivering $6.7 \%$ compared to $5 \%$ in our study.[25]

Kizilirmak et al used $30 \mathrm{mg} / \mathrm{kg}$ bolus as the treatment for postoperative shivering following general anaesthesia and found that it was as effective as meperidine, but meperidine stopped shivering slightly faster than magnesium.[6] None of the differences, however, was statistically significant.[26] Hypotension is due to the vasodilating effect of MgSO4. This property was used by Ryu et al, to induce controlled hypotension in middle ear surgery.[27] and also reduce blood loss during endoscopic sinus surgery.[28]

\section{CONCLUSION}

From our study we conclude that for spinal anaesthesia, prophylactic MgSO4 infusion lowered incidence of shivering. Inj. Pethidine also proved to be an effective treatment when postspinal shivering occurred with minimal side effects.

\section{REFERENCES}

1. Frank SM, Higgins MS, Breslow MJ, et al. The catecholamine, cortisol and hemodynamic responses to mild perioperative hypothermia: a randomized clinical trial. Anesthesiology 1995;82(1):83-93.

2. De Witte J, Sessler DI. Perioperative shivering: physiology and pharmacology. Anesthesiology 2002;96(2):467-84.

3. Mizobe T, Nakajima Y, Sunaguchi $M$, et al. Clonidine produces a dose-dependent impairment of baroreflexmediated thermoregulatory responses to positive endexpiratory pressure in anesthetized humans. Br J Anaesth 2005;94(4):536-41.

4. Kranke P, Eberhart LH, Roewer N, et al. Single-dose parenteral pharmacological interventions for the prevention of postoperative shivering: a quantitative systematic review of randomized controlled trials. Anesth Analg 2004;99(3):718-27.

5. Ikeda T, Kazama T, Sessler DI, et al. Induction of anesthesia with ketamine reduces the magnitude of redistribution hypothermia. Anesth Analg 2001;93(4):934-8.

6. Kizilirmak S, Karakas SE, Akca O, et al. Magnesium sulfate stops postanesthetic shivering. Ann N Y Acad Sci 1997;813:799-806.

7. Zweifler RM, Voorhees ME, Mahmood MA, et al. Magnesium sulfate increases the rate of hypothermia via surface cooling and improves comfort. Stroke 2004;35(10):2331-4.

8. Cotton DB, Hallak M, Janusz C, et al. Central anticonvulsant effects of magnesium sulfate on n-methyl-d-aspartateinduced seizures. Am J Obstet Gynecol 1993;168(3 Pt 1):974-8.

9. Lee C, Zhang X, Kwan WF. Electromyographic and mechanomyographic characteristics of neuromuscular block by magnesium sulphate in the pig. Br J Anaesth 1996;76(2):278-83.

10. Rukshin V, Shah PK, Cercek B, et al. Comparative antithrombotic effects of magnesium sulfate and the platelet glycoprotein IIb/IIIa inhibitors tirofiban and eptifibatide in a canine model of stent thrombosis. Circulation 2002;105(16):1970-5.

11. Bromage PR. Epidural analgesia. Philadelphia: WB Saunders Company 1978:394-6.

12. Crossley AW, Mahajan RP. The intensity of postoperative shivering is unrelated to axillary temperature. Anaesthesia 1994;49(3):205-7.

13. Jeon YT, Jeon YS, Kim YC, et al. Intrathecal clonidine does not reduce post-spinal shivering. Acta Anaesthesiol Scand 2005;49(10):1509-13.

14. Matsukawa T, Sessler DI, Christensen R, et al. Heat flow and distribution during epidural anesthesia. Anesthesiology 1995;83(5):961-7. 
15. Kurz A, Sessler DI, Schroeder M, et al. Thermoregulatory response thresholds during spinal anesthesia. Anesth Analg 1993;77(4):721-6.

16. Kaoy CK, Chan WY, Chin MK. Shivering during regional anaesthesia and its control with pethidine. Singapore Med J 1991;32(3):160-2.

17. Reddy VS, Chiruvella S. Clonidine versus tramadol for postspinal shivering during caesarean section: a randomized, double blind clinical study. J Obstet Anaesth Crit Care 2011;1(1):26-9.

18. James MF. Magnesium: an emerging drug in anaesthesia. Br J Anaesth 2009;103(4):465-7.

19. Akhtar MI, Ullah H, Hamid M. Magnesium, a drug of diverse use. J Pak Med Assoc 2011;61(12):1220-5.

20. Lew M, Klonis E. Emergency management of eclampsia and severe preeclampsia. Emerg Med (Fermantle) 2003;15(4): 361-8.

21. Wadhwa A, Sengupta P, Durrani J, et al. Magnesium sulphate only slightly reduces the shivering threshold in humans. Br J Anaesth 2005;94(6):756-62.

22. Talke P, Tayefeh F, Sessler DI, et al. Dexmedetomidine does not alter the sweating threshold, but comparably and linearly reduces the vasoconstriction and shivering thresholds. Anesthesiology 1997;87(4):835-41.
23. Matsukawa T, Hanagata $\mathrm{K}$, Ozaki M, et al. IM midazolam as premedication produces a concentration-dependent decrease in core temperature in male volunteers. $\mathrm{Br} \mathrm{J}$ Anaesth 1997;78(4):396-9.

24. Thwaites CL, Yen LM, Loan HT, et al. Magnesium sulphate for treatment of severe tetanus: a randomised controlled trial. Lancet 2006;368(9545):1436-43.

25. Gozdemir M, Usta B, Demircioglu RI, et al. Magnesium sulfate infusion prevents shivering during transurethral prostatectomy with spinal anesthesia. A randomized, double blinded, controlled study. J Clin Anesth 2010;22(3):184-9.

26. Lysakowski C, Dumont L, Czarnetzki C, et al. Magnesium as an adjuvant to postoperative analgesia: a systematic review of randomized trials. Anesth Analg 2007;104(6): 1532-9.

27. Ryu JH, Sohn IS, Do SH. Controlled hypotension for middle ear surgery: a comparison between remifentanil and magnesium sulphate. Br J Anaesth 2009;103(4):490-5.

28. Elsharnouby NM, Elsharnouby MM. Magnesium sulphate as a technique of hypotensive anaesthesia. Br J Anaesth 2006;96(6):727-31. 